\title{
Fusaric Acid as a Novel Proton-Affinitive Derivatizing Reagent for Highly Sensitive Quantification of Hydroxysteroids by LC-ESI-MS/MS
}

\author{
Kouwa Yamashita, Keiko Yamazaki, Sachiko Komatsu, and \\ Mitsuteru Numazawa \\ Faculty of Pharmaceutical Sciences, Tohoku Pharmaceutical University, Sendai, Japan
}

A highly sensitive derivatization method for liquid chromatography (LC)-electrospray ionization (ESI) tandem mass spectrometry of dehydroepiandrosterone (DHEA), testosterone (T), pregnenolone (P5), and 17 $\alpha$-OH-pregnenolone (17-OHP5) was developed based on the use of fusaric acid as a reagent. DHEA, P5, and 17-OHP5 were rapidly and quantitatively converted to the 3-fusarate esters by treatment with fusaric acid and 2-methyl-6-nitrobenzoic anhydride. The positive ESI-mass spectra of the fusarate esters of each steroid were dominated by the appearance of $\left[\mathrm{M}+\mathrm{H}^{+}\right.$as base peaks. The fusarate derivatization of these steroids showed 17.6-fold (DHEA), 11.9-fold (P5), 3.3-fold (17OHP5), and 1.8-fold (T) higher sensitivity to those of the corresponding picolinate derivatives in LC-selected reaction monitoring. (J Am Soc Mass Spectrom 2010, 21, 249-253) (c) 2010 American Society for Mass Spectrometry

I the recent development of analytical methodology for hydroxysteroids that were generally insensitive to liquid chromatography-electrospray ionization tandem mass spectrometry (LC-ESI-MS/MS), two types of derivatization designs have been proposed to provide high sensitivity to such kind of steroid molecules. The introduction of permanently charged moieties into steroid molecules was proven to be a promising method [1-4]. The use of 1-methylpyridinium for hydroxy group [2] and 2-hydrazino-1-methylpyridine for carbonyl group [4] as derivatizing reagents showed higher sensitivity in analyses of testosterone (T), $5 \alpha$-dihydrotestosterone (DHT), and dehydroepiandrosterone (DHEA) by LC-ESI-MS/MS. However, the application of these permanently charged derivatives to steroids possessing more than two hydroxy and/or carbonyl groups in one molecule seemed to be inconvenient and failed to obtain simple ESI-mass spectra with the appearance of protonated molecule $\left([\mathrm{M}+\mathrm{H}]^{+}\right)$ due to the formation of multiple ions of $[\mathrm{M}-\mathrm{H}]^{-}$and $[\mathrm{M}]^{2+}[4]$.

The introduction of high proton-affinitive moiety into steroid molecules was the alternative choice to obtain simple ESI mass spectra characterized by the formation of $[\mathrm{M}+\mathrm{H}]^{+}$with high intensity [5-8]. The use of dimethylaminoaphthalene-sulfonate [5,6], pyridine-sulfonate [7], pyridine-dicarboxylate [8] deriva-

Address reprint requests to Dr. K. Yamashita, Faculty of Pharmaceutical Sciences, Tohoku Pharmaceutical University, 4-1 Komatsushima 4-chome, Aoba-ku, Sendai-shi, Miyagi-ken 981-8558, Japan. E-mail: kyama@tohokupharm.ac.jp tives for steroidal hydroxyl group, and hydroxime [9, 10] and 2-pyridine-hydrazone [11] derivatives for steroidal ketones have been investigated. However, the introduction of sulfonate moieties was limited to the phenolic hydroxy group of estrogens. Derivatization of $\mathrm{T}$ and DHT with pyridine-2,3-dicarboxylic anhydride resulted in the formation of the mixture consisted of two regio-isomers of half esters in their chromatograms [8]. Generation of syn- and ant-isomeric peaks might also be inevitable in the analyses of T and DHT using hydroxime and pyridine-hydrazone derivatizations $[9,11]$.

Recently, we have demonstrated that the introduction of picolinate moiety into hydroxysteroids provided some advantages to LC-ESI-MS/MS analyses of these compounds in a positive mode, involving the production of simple $[\mathrm{M}+\mathrm{H}]^{+}$with high intensity, the simplicity of the derivatization and purification process [12-14], and the excellence for liquid chromatographic behaviors in the profile analyses of corticosteroids [1517] and sterols [18-20]. In our preliminary results, the picolinate derivatives of $\Delta^{5}-3 \beta$-hydroxysteroids, such as DHEA and pregnenolone (P5), seemed to be less sensitive in ESI compared with those of $\mathrm{T}$ and estradiol by selected reaction monitoring (SRM). This report describes the characteristics of fusaric acid derivative, as a novel and sensitive proton-affinitive tag for hydroxysteroids in LC-ESI-MS/MS, and presents some possible explanations to the enhancement of detection sensitivity by this derivative in LC-ESI-MS/MS compared with the picolinic acid derivative. 


\section{Experimental}

\section{Materials and Reagents}

Dehydroepiandrosterone (DHEA, 1a), testosterone (T, 2a), pregnenolone (P5, 3a), and $17 \alpha$-hydroxypregnenolone (17-OHP5, 4a) were purchased from Steraloids (Newport, RI, USA). Fusaric acid was obtained from SigmaAldrich (St. Louis, MO, USA), and 2-methyl-6-nitrobenzoic anhydride, 4-dimethylaminopyridne, and triethylamine were obtained from Tokyo Kasei Kogyo (Tokyo, Japan). LC-MS grade ultra pure water, acetonitrile $(\mathrm{MeCN})$, and methanol $(\mathrm{MeOH})$ were purchased from Wako Pure Chemicals (Osaka, Japan). Oasis HLB cartridge ( $30 \mathrm{mg}, 1 \mathrm{~mL}$ ) was obtained from Waters (Milford, MA, USA).

\section{LC-ESI-MS/MS}

LC-ESI-MS/MS was run on a Finnigan TSQ Quantum triple-stage quadrupole mass spectrometer (Thermo Fischer Scientific, San Jose, CA, USA) equipped with an ESI ion source and a Surveyor auto-sampler and a MS-pump (Thermo Fischer Scientific). The columns was a Puresil $5-\mathrm{C}_{18}(150 \mathrm{~mm} \times 2.1 \mathrm{~mm}$ i.d., $5 \mu \mathrm{m}$, Waters $)$ connected to a guard cartridge $\left(\mathrm{C}_{18}, 10 \mathrm{~mm} \times 2 \mathrm{~mm}\right.$ i.d., $5 \mu \mathrm{m})$ in a guard-cartridge holder with the mobile phase consisted of MeCN-ultrapure water-acetic acid $(\mathrm{AcOH})(85: 15: 0.1, \mathrm{vol} / \mathrm{vol} / \mathrm{vol})$ at a flow rate of 200 $\mu \mathrm{L} / \mathrm{min}$. Elution was performed with an isocratic mode and at an ambient temperature. The general ESI-MS conditions were as follows: spray voltage, $4500 \mathrm{~V}$ (positive); sheath gas, nitrogen, 30 arbitrary unit (gas pressure); auxiliary gas, nitrogen, 15 arbitrary unit (gas pressure); ion transfer capillary temperature, $350{ }^{\circ} \mathrm{C}$; collision gas argon, 1.5 mTorr (gas pressure).

\section{Synthesis of Standard Derivatives}

To a solution of DHEA (1a, $50 \mathrm{mg}$; $0.17 \mathrm{mmol}$ in tetrahydrofuran (THF) $1 \mathrm{~mL}$ ) was added the premixed reagent solution (fusaric acid; $40 \mathrm{mg}$, 2-methyl-6-nitrobenzoic anhydride: $50 \mathrm{mg}$, 4-dimethylaminopyridine; $10 \mathrm{mg}$, triethylamine; $50 \mu \mathrm{L}$, THF $1 \mathrm{~mL}$ ), and the reaction mixture was stirred at room temperature for $1 \mathrm{~h}$. After dilution of the reaction mixture with 5\% $\mathrm{NaHCO}_{3}(20 \mathrm{~mL})$, the product was then extracted with ethyl acetate EtOAc $(20 \mathrm{~mL})$. The organic layer was washed with sat. $\mathrm{NaCl}(20 \mathrm{~mL}), 5 \% \mathrm{HCl}(20 \mathrm{~mL})$, and then with sat. $\mathrm{NaCl}(20 \mathrm{~mL} \times 2)$, and dried over anhydrous $\mathrm{Na}_{2} \mathrm{SO}_{4}$. Evaporation of the solvent and re-crystallization of the crude product from EtOAc afforded compound $\mathbf{1 c}$ as colorless leaflets. Similarly, $\mathbf{2 c}$ (colorless prisms), $3 \mathrm{c}$ (colorless needles), and $4 \mathrm{c}$ (colorless prisms) were prepared from $\mathbf{2 a}, \mathbf{3} \mathbf{a}$, and $\mathbf{4 a}$, respectively. Picolinate derivatives ( $3 \mathbf{b}$ : colorless needles and $4 \mathrm{~b}$ : colorless needles) were synthesized in the same manner as $\mathbf{1 b}$ and $\mathbf{2} \mathbf{b}$, and the structures of all derivatives were confirmed by the measurement of ${ }^{1} \mathrm{H}$ nuclear magnetic resonance spectra, ultra violet spectra, and elemental analyses as previously described [12].

\section{Microscale Derivatization [13, 14]}

To a solution of steroid $(\mathbf{1 a}, \mathbf{2} \mathbf{a}, \mathbf{3 a}$, or $\mathbf{4 a}: 1 \mathrm{ng}$ or $1 \mu \mathrm{g}$ in THF $50 \mu \mathrm{L}$ ) were added the premixed reagent solution $(20 \mu \mathrm{L})$ (fusaric acid; $40 \mathrm{mg}$, 2-methyl-6-nitrobenzoic anhydride; $50 \mathrm{mg}$, 4-dimethylaminopyridine; $10 \mathrm{mg}$, triethylamine; $100 \mu \mathrm{L}$ in THF $1 \mathrm{~mL}$ ), and the resulting mixture was allowed to stand at room temperature for 30 min. After dilution of the reaction mixture with $5 \%$ $\mathrm{NaHCO}_{3}(1 \mathrm{~mL})$, the resulting sample was transferred onto Oasis HLB cartridge $(30 \mathrm{mg}-1 \mathrm{~mL}$, preconditioned with $\mathrm{MeOH} 1 \mathrm{~mL}$ and ultra pure water $1 \mathrm{~mL}$ ). The cartridge was washed with ultra pure water $(3 \mathrm{~mL}), 5 \%$ $\mathrm{HCl}(3 \mathrm{~mL})$, and ultra pure water $(3 \mathrm{~mL})$, and the derivative was eluted with $90 \% \mathrm{MeCN}(1 \mathrm{~mL})$. The eluate was evaporated to dryness under reduced pressure and the residue was dissolved in mobile phase $(100 \mu \mathrm{L})$ and then submitted to LC-ESI-MS/MS. Reaction yield was calculated by comparing the peak intensity prepared in this section with that of the sample obtained and purified in the former section (Synthesis of standard) by SRM.

\section{Results and Discussion}

As shown in Figure 1, the fusaric acid moiety was incorporated into the steroid molecule via $3 \beta$-hydroxy

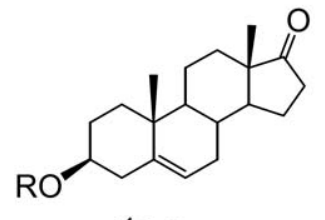

1a-c

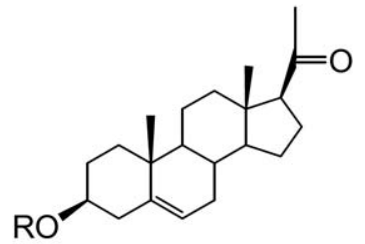

$3 a-c$
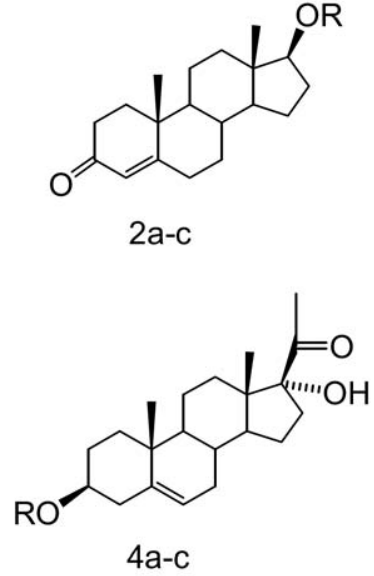

a: $\mathrm{R}=\mathrm{H}$

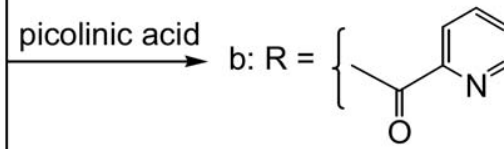

$\underset{\mathrm{fusaric} \text { acid }}{\stackrel{\mathrm{f}}{\mathrm{f}} \mathrm{R}=\{\mathrm{O}}$
Figure 1. Schematic presentation of the derivatization of DHEA (1a), T (2a), P5 (3a) and 17-OHP5 (4a) with picolinic acid and fusaric acid by mixed anhydride method using 2-methyl-6nitrobenzoic anhydride. 
group (1a, 3a, 4a) or $17 \beta$-hydroxy group (2a) by ester formation with mixed anhydride method using 2methyl-6-nitrobenzoic anhydride [21] and 4-dimethylaminopyridine. Fusarate formation by this method underwent quantitatively under mild condition with reaction yield of $>85 \%$ for $1 c, 2 c, 3 c$, and $4 c$ in the levels of $1 \mathrm{ng}$ and $1 \mu \mathrm{g}$ as was observed in the pocolinate derivatization $[13,14]$.

Figure 2 shows the positive ESI mass spectrum (a) and the product ion spectrum (b) of the fusarate derivative of DHEA (1c). Positive-ESI-mass spectrum of 1c was dominated by the appearance of protonated molecule $\left([\mathrm{M}+\mathrm{H}]^{+}\right)$at $m / z 450$ as a base peak, and the formation of adduct ions $\left(\left[\mathrm{M}+\mathrm{Na}+\mathrm{CH}_{3} \mathrm{CN}\right]^{+}\right)$was observed at $m / z$ 513. Collison of $[\mathrm{M}+\mathrm{H}]^{+}$with argon (collision energy: $21 \mathrm{~V}$ ) resulted in the formation of product ions at $\mathrm{m} / \mathrm{z} 271$ and 253, these ions were assigned to be formed by the elimination of fusaric acid $\left(\mathrm{C}_{10} \mathrm{H}_{13} \mathrm{NO}_{2}\right)$ moiety followed by the additional dehydration from $[\mathrm{M}+\mathrm{H}]^{+}$in 1c. The formation of these kinds of product ions is not specific to the fusarate derivatives, and is commonly observed in the picolinate derivatives and other pyridine-carboxylate derivatives of $\mathbf{1 a}$ and $\mathbf{2 a}$ as previously reported $[12,14]$. Table 1 summarizes the positive-ESI mass and product ion spectral data of these four fusarate derivatives (1c, 2c, $3 c$, and 4c). The same product ion species were observed at $m / z 271$ and 253 in 2c, $m / z 299$ and 281 in 3c, and $m / z 315$ and 297 in $4 c$, respectively. The formation of product ion at $\mathrm{m} / \mathrm{z} 180$ originated from the fusaric acid moiety was also observed in all cases, and dominated particularly in $\mathbf{2 c}$.
In SRM, the transitions of $m / z 450 \rightarrow m / z 271$ (or $m / z$ 253) for $1 \mathrm{c}$ and $2 \mathrm{c}, \mathrm{m} / \mathrm{z} 478 \rightarrow \mathrm{m} / \mathrm{z} 281$ for $3 \mathrm{c}$ and $\mathrm{m} / \mathrm{z}$ $494 \rightarrow m / z 297$ for $4 c$, were chosen, respectively, and detection sensitivities were compared with those of the picolinate derivatives $(\mathbf{1 b}, \mathbf{2 b}, \mathbf{3 b}$, and $\mathbf{4 b})$. The results are shown in Table 1 (right column). When the detection sensitivity was evaluated by measuring the signalto-noise (SN) ratios for each peak of $20 \mathrm{fg}$ (injected amount), the values of $1 c, 2 c, 3 c$, and $4 c$ were $>60,2,15$, and 8 , respectively. These $\mathrm{SN}$ ratios were higher to those of the corresponding picolinate derivatives. The increase of SN ratio was remarkable in $\mathbf{1 c}, 3 \mathbf{c}$, and $4 \mathrm{c}$ rather than 2c. When absolute detection responses of the fusarate derivatives were compared with those of the corresponding picolinate derivatives by SRM (0.1 pmol; injected amount), the fusarate derivatives of each steroid exhibited higher responses than those of the picolinate derivatives. The fusarate derivative of $\mathrm{T}(\mathbf{2 c})$ showed $1.8 \pm 0.2$ (mean \pm standard deviation; $n=$ 3 )-fold higher response to that of $\mathbf{2 b}$, whereas, the fusarate derivatives of DHEA (1c), P5 (3c), and 17OHP5 (4c) showed $17.6 \pm 3.0$-fold, $11.9 \pm 2.4$-fold, and $3.3 \pm 1.0$-fold higher responses when compared with those of $1 b, 3 b$, and $4 b$, respectively. The typical SRM chromatograms of these steroids in matrices is explained in the Supplementary Material, which can be found in the electronic version of this article.

As judged from these results, the derivatization of steroidal hydroxy group by fusaric acid must be a promising technique to afford an excellent sensitivity to the assay of DHEA, P5, and 17-OHP5 by LC-ESI-MS/ MS. Appearance of the differences in SRM sensitivity

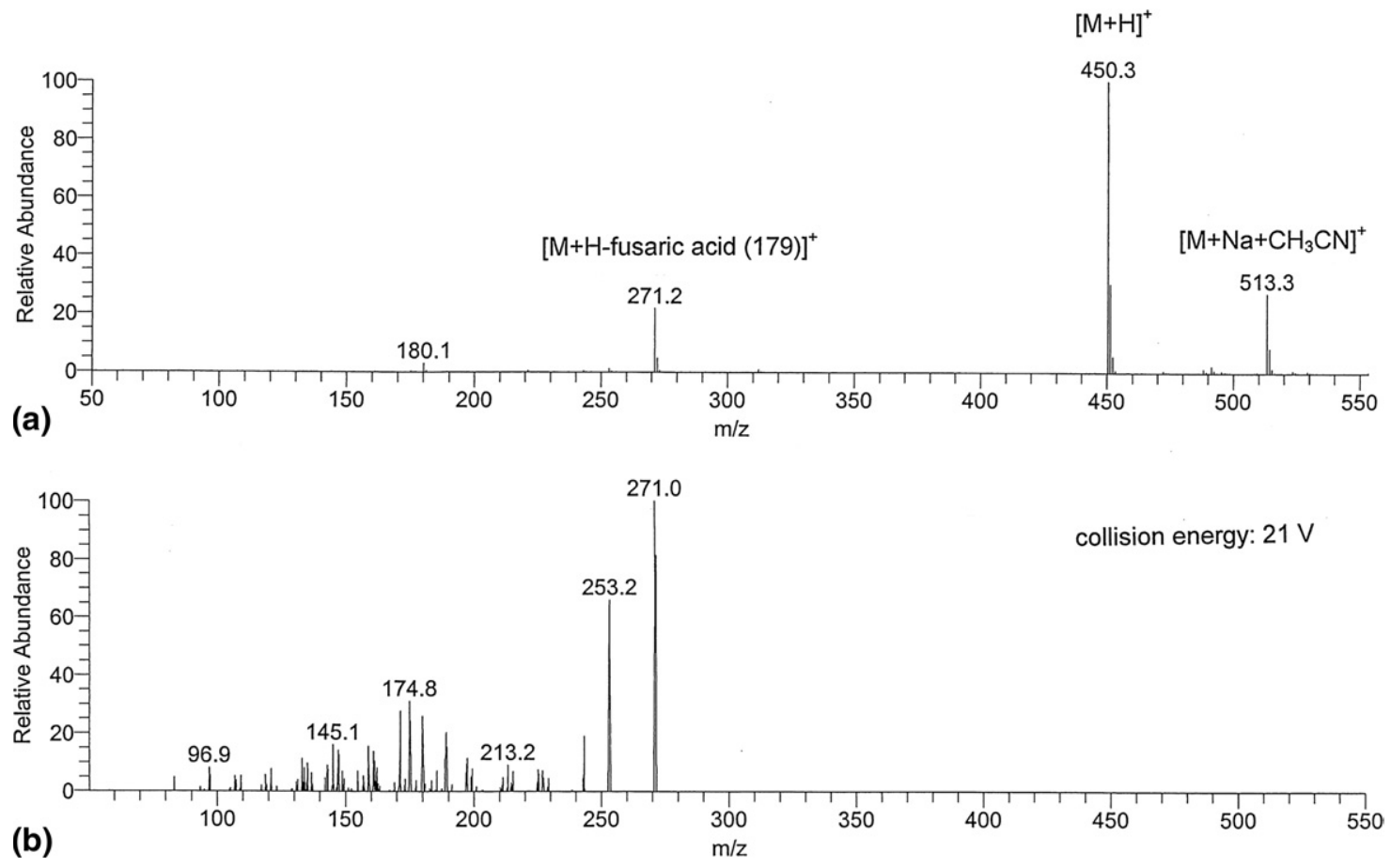

Figure 2. Positive ESI mass spectrum (a) and product ion spectrum (b) of the fusarate derivative of DHEA (1c). Spray voltage: $4500 \mathrm{~V}$. 
Table 1. ESI-mass spectral, tandem mass spectral data and signal-to-noise (SN) ratios in SRM of the fusarate derivatives of DHEA (1c), T (2c), P5 (3c), and 17-OHP5 (4c)

\begin{tabular}{|c|c|c|c|c|c|c|}
\hline \multirow{3}{*}{$\begin{array}{c}\text { Derivatives } \\
\text { 1c }\end{array}$} & \multicolumn{2}{|c|}{ ESI-MS data: $m / z$ (intensity, \%) } & \multirow{2}{*}{\multicolumn{3}{|c|}{$\begin{array}{l}\text { MS/MS data: product ions } \mathrm{m} / \mathrm{z} \\
\text { (collision energy; } \mathrm{V})\end{array}$}} & \multirow{3}{*}{$\begin{array}{c}\text { SN ratios } \\
(20 \mathrm{fg} / \text { on column })^{\mathrm{a}} \\
>20^{\mathrm{d}},>60^{\mathrm{e}}\end{array}$} \\
\hline & \multirow{2}{*}{ 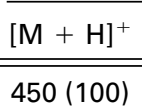 } & \multirow{2}{*}{$\frac{\text { Other ions }}{2513^{\mathrm{b}}(35), 271^{\mathrm{c}}(28)}$} & & & & \\
\hline & & & $271(21)$ & $253(28)$ & $180(21)$ & \\
\hline 2c & $450(100)$ & $513^{\mathrm{b}}(16), 271^{\mathrm{c}}(1)^{\mathrm{c}}$ & $180(20)$ & $253(27)$ & $271(22)$ & $2^{d}$ \\
\hline 3c & $478(100)$ & $541^{b}(21), 299^{c}(22)$ & $299(16)$ & $281(21)$ & $180(18)$ & $15^{f}$ \\
\hline 4c & $494(100)$ & $557^{\mathrm{b}}(18), 315^{\mathrm{c}}(50)$ & $297(21)$ & $315(19)$ & $180(19)$ & $8^{g}$ \\
\hline
\end{tabular}

aalues were expressed as injected amounts.

${ }^{\mathrm{b}}\left[\mathrm{M}+\mathrm{Na}+\mathrm{CH}_{3} \mathrm{CN}\right]^{+}$

c $\left[\mathrm{M}+\mathrm{H}-\mathrm{C}_{10} \mathrm{H}_{13} \mathrm{O}_{2} \mathrm{~N} \text { (fusaric acid) }-\mathrm{H}_{2} \mathrm{O}\right]^{+}$.

${ }^{\mathrm{d}} \mathrm{m} / \mathrm{z} 450 \rightarrow m / z 253$ (27 V).

e $m / z 450 \rightarrow m / z 271$ (21 V).

${ }^{\mathrm{f}} \mathrm{m} / \mathrm{z} 478 \rightarrow \mathrm{m} / z 281(21 \mathrm{~V})$.

${ }^{\mathrm{g}} \mathrm{m} / \mathrm{z} 494 \rightarrow \mathrm{m} / \mathrm{z} 297$ (21 V).

between the fusarate derivatives and picolinate derivatives for these hydroxysteroid partially are supposed to be attributed to the theoretically higher value of the proton-affinity of 5-butylpyridine (fusarate) moiety (ca 229-230 kcal/mol, estimated value from the database; http:/ / webbook.nist.gov/chemistry/ of National Institute of Standard and Technology (NIST)) than that of pyridine moiety (ca $222.4 \mathrm{kcal} / \mathrm{mol}$ ). The reason for the observation of difference in the enhancement of sensitivity between $\mathrm{T}$ and DHEA was not made clear at this moment.

\section{Conclusions}

Derivatization of hydroxysteroids with fusaric acid and the characterization of the prepared derivatives in LCESI-MS/MS (positive mode) were described. The use of fusarate derivatization for $\Delta^{5}$-3 $\beta$-hydroxysteroids provided robustness and enhanced sensitivity to the assay, and enabled to determine these steroids with the levels of less than sub-femtogram on column. Improvement of sensitivity of fusarate derivative in LC-ESI-MS/MS might partially be attributed to the inherent high proton-affinity of fusarate moiety than that of the picolinate moiety.

\section{Acknowledgments}

The authors acknowledge support in part for this work by a High Technology Research Center Project from the Ministry of Education, Culture, Sports, Science, and Technology of Japan.

\section{Appendix A Supplementary Material}

Supplementary material associated with this article may be found in the online version at doi:10.1016/ j.jasms.2009.10.008.

\section{References}

1. Quirke, J. M. E.; Adam, C. L.; Van Berkel, G. J. Chemical Derivatization for Electrospray Ionization Mass Spectrometry. 1. Alkyl halides, Alcohols, Phenols, Thiols, and Amines. Anal. Chem. 1994, 66, 1302-1305.
2. Nishiyama, T.; Hashimoto, Y.; Takahashi, K. The Influence of Androgen Deprivation Therapy on Dihydrotestosterone Levels in the Prostatic Tissue of Patients with Prostate Cancer. Cancer. Res. 2004 10, 7121-7126.

3. Griffith, W. J.; Liu, S.; Alvelius, G.; Sjvöll, J. Derivatization for the Characterization of Neutral Oxosteroids by Electrospray and MatrixAssisted Laser Desorption/Ionization Mass Spectrometry. Rapid Commun. Mass Spectrom. 2003, 17, 924-935.

4. Higashi, T.; Yamauchi, A.; Shimada, K. 2-Hydradino-1-Methylpyridine: A Highly Sensitive Derivatization Reagent for Oxosteroids in Liquid Chromatography-Electrospray Ionization Mass Spectrometry. J. Chromatogr. B 2005, 825, 214-222.

5. Xu, X.; Veenstra, T. D.; Fox, S. D.; Roman, J. M.; Issaq, H. J.; Falk, R.; Saavedra, J. E.; Keefer, L. K.; Ziegler, R. G. Measuring Fifteen Endogenous Estrogens Simultaneously in Human Urine by HighPerformance Liquid Chromatography-Mass Spectrometry. Anal. Chem. 2005, 77, 6646-6654.

6. Salvador, A.; Moretton, C.; Piram, A.; Faure, R. On-Line Solid Phase Extraction with On-Support Derivatization for High-Sensitivity Liquid Chromatography Tandem Mass Spectrometry of Estrogens in Influent/ Effluent of Wastewater Treatment Plants. J. Chromatogr. A 2007, 1145, 102-109.

7. Xu, L.; Spink, D. C. Analysis of Steroidal Estrogens as Pyridine-3Sulfonyl Derivatives by Electrospray Tandem Mass Spectrometry. Anal. Biochem. 2008, 375, 105-114.

8. Licea-Perez, H.; Wang, S.; Szapacs, M. E.; Yang, E. Development of a Highly Sensitive and Selective UPLC/MS/MS Method for the Simultaneous Determination of Testosterone and $5 \alpha$-Dihydrotestosterone in Human Serum to Support Testosterone Replacement Therapy for Hypogonadism. Steroids 2008, 73, 601-610.

9. Kalhorn, T. F.; Page, S. T.; Howald, W. N.; Mostaghel, E. A.; Nelson, P. S. Analysis of Testosterone and Dihydrotestosterone from Biological Fluids as the Oxime Derivatives Using High-Performance Liquid Chromatography/Tandem Mass Spectrometry. Rapid Commun. Mass Spectrom. 2007, 21, 3200-3206.

10. Kushnir, M. M.; Rockwood, A. L.; Roberts, W. L.; Pattison, E. G. Bunker, A. M.; Fitzgerald, R. L.; Meikle, A. W. Performance Characteristics of a Novel Tandem Mass Spectrometry Assay for Serum Testosterone. Clin. Chem. 2006, 52, 120-128.

11. Shibayama, Y.; Higashi, T.; Shimada, K.; Kashimada, K.; Onishi, T.; Ono, M.; Miyai, K.; Mizutani, S. Liquid Chromatography-Tandem Mass Spectrometric Method for Determination of Salivary 17\&; $\alpha$ Hydroxyprogesterone: A Noninvasive Tool for Evaluating Efficacy of Hormone Replacement Therapy in Congenital Adrenal Hyperplasia. J. Chromatogr. B 2008, 867, 49-56.

12. Yamashita, K.; Kobayashi, S.; Tsukamoto, S.; Numazawa, M. Synthesis of Pyridine-Carboxylate Derivatives of Hydroxysteroids for Liquid Chromatography-Electrospray Ionization-Mass Spectrometry. Steroids 2007, 72, 50-59.

13. Yamashita, K.; Okuyama, M.; Watanabe, Y.; Honma, S.; Kobayashi, S. Numazawa, M. Highly Sensitive Determination of Estrone and Estradiol in Human Serum by Liquid Chromatography-Electrospray Ionization Tandem Mass Spectrometry. Steroids 2007, 72, 819-827.

14. Yamashita, K.; Yoshimichi, M.; Maekubo, H.; Okuyama, M.; Honma, S.; Takahashi, M.; Numazawa, M. Development of Highly Sensitive Quantification Method for Testosterone and Dihydrotestosterone in Human Serum and Prostate Tissue by Liquid Chromatography-Electrospray Ionization Tandem Mass Spectrometry. Steroids 2009, 74, 920-926.

15. Yamashita, K.; Takahashi, M.; Tsukamoto, S.; Numazawa, M. Okuyama, M.; Honma, S. Use of Novel Derivatization for Simultaneous Quantification of Six Corticosteroids by Liquid ChromatographyElectrospray Ionization Tandem Mass Spectrometry. J. Chromatogr. A 2007, 1173, 120-128.

16. Yamashita, K.; Nakagawa, R.; Okuyama, M.; Honma, S.; Takahashi, M.; Numazawa, M. Simultaneous Determination of Tetrahydrocortisol, 
Allotetrahydrocortisol, and Tetrahydrocortisone in Human Urine by Liquid Chromatography-Electrospray Ionization Mass Spectrometry. Steroids 2008, 73, 727-737.

17. Yamashita, K.; Okuyama, M.; Nakagawa, R.; Honma, S.; Satoh, F.; Morimoto, R.; Ito, S.; Takahashi, M.; Numazawa, M. Development of Sensitive Derivatization Method for Aldosterone in Liquid Chromatography-Electrospray Ionization Mass Spectrometry of Corticosteroids. J. Chromatogr. A 2008, 1200, 115-121.

18. Honda, A.; Yamashita, K.; Numazawa, M.; Ikegami, T.; Doy, M.; Matsuzaki, Y.; Miyazaki, H. Highly Sensitive Quantification of $7 \alpha-$ Hydroxy-4-Cholesten-3-one in Human Serum by LC-ESI-MS/MS. J. Lipid Res. 2007, 48, 459-464.
19. Honda, A.; Yamashita, K.; Miyazaki, H.; Shirai, M.; Ikegami, T.; Xu, G.; Numazawa, M.; Hara, T.; Matsuzaki, Y. Highly Sensitive Analysis of Stero Profiles in Human Serum by LC-ESI-MS/MS. J. Lipid Res. 2008, 49, 2063-2073.

20. Honda, A.; Yamashita, K.; Hara, T.; Ikegami, T.; Miyazaki, T.; Shirai, M.; Xu, G.; Numazawa, M.; Matsuzaki, Y. Highly Sensitive Quantification of Key Regulatory Oxysterols in Biological Samples by LC-ESI-MS/MS J. Lipid Res. 2008, 50, 350-357.

21. Shiina, I.; Ibuka, R.; Kubota, M. A New Condensation Reaction for the Synthesis of Carboxylic Esters from Nearly Equimolar Amounts of Carboxylic Acids and Alcohols Using 2-Methyl-6-Nitrobenzoic Anhydride. Chem. Lett. 2002, 31, 286-287. 